\title{
Probiotic treatment in the oral cavity: An update
}

\author{
Antonio-Juan Flichy-Fernández ${ }^{1}$, Teresa Alegre-Domingo ${ }^{1}$, David Peñarrocha-Oltra ${ }^{2}$, Miguel Peñarrocha- \\ Diago $^{3}$ \\ ${ }^{1}$ Master of Oral Surgery and Implantology. Valencia University Medical and Dental School \\ ${ }^{2}$ Student of the Master of Oral Surgery and Implantology. Valencia Univesity Medical and Dental School \\ ${ }^{3}$ Professor of Oral Surgery. Director of the Master of Oral Surgery and Implantology. Valencia University Medical and Dental \\ School
}

Correspondence:

Cirugia Bucal. Clínicas Odontológicas

Gascó Oliag 1

46021-Valencia

Miguel.Penarrocha@uv.es

Flichy-Fernández AJ, Alegre-Domingo T, Peñarrocha-Oltra D, Peñarrocha-Diago M. Probiotic treatment in the oral cavity: An update. Med Oral Patol Oral Cir Bucal. 2010 Sep 1;15 (5):e677-80.

http://www.medicinaoral.com/medoralfree01/v15i5/medoralv15i5p677.pdf

Received: 03/02/2009 Accepted: 22/01/2010

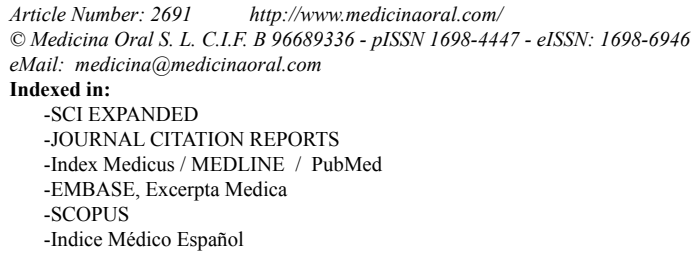

\begin{abstract}
Probiotics have been found to be beneficial to host health. Their primary use in medicine has been for the management of intestinal tract problems.

In recent years, probiotics have been used as a treatment to promote oral health. The aim of the present study was to review published studies regarding probiotics and their effects on the oral cavity. Studies reporting the anticariogenic effects of probiotics, their use in the treatment of periodontal disease, a reduced crevicular fluid volume and cytokine content, as well as their use in the treatment of halitosis and Candida albicans were identified. Studies assessing residence time of probiotics in the oral cavity were also selected for retrieval. Most authors concluded that the use of oral probiotics was associated with an improvement in oral health, including a significantly reduced level of cariogenic and periodontal pathogens and a lower crevicular fluid volume and cytokine concentration.
\end{abstract}

Key words: Probiotics, oral health, cariogenic bacteria, periodontal disease, halitosis, Candida albicans.

\section{Introduction}

Probiotics were defined by FAO/WHO (The Food Agricultural Organization/World Health Organization) as live microorganisms which when administered in adequate amounts (in food or as a dietary supplement) confer a health benefit on the host (improving microbiological balance in intestinal tract) $(1,2)$. Such nonpathogenic organisms (yeasts or bacteria, particularly lactic acid bacteria) are present in food, and can have a favorable impact on host health. Probiotics have bee used for decades in fermented products, but potential use of probiotics as a nutritional medical therapy has not been formally acknowledged (2).

Metchnikoff was the first to state that probiotics could provide a health benefit, and proposed that Bulgarian people had a longer longevity due to fermented milk containing viable bacteria. "Probiotic" term, as opposed to "antibiotic", was initially proposed by Lilley 
and Stillwell in 1965. First probiotic species to be introduced in research was Lactobacillus acidophilus by Hull et al. in 1984; followed by Bifidobacterium bifidum by Holcombh et al. in 1991 (3).

Probiotics can improve patient condition in medical disorders such as diarrhea, gastroenteritis, short-bowel syndrome, and inflammatory intestinal diseases (Crohn's disease and ulcerative colitis), cancer, immunodepressive states, inadequate lactase digestion, pediatric allergies, growth retardation, hyperlipidemia, liver diseases, infections with Helicobacter pylori, genitourinary tract infections, and others; all such findings have been supported by several studies demonstrating improved results after using probiotics (2-4).

Currently available information on oral probiotic uses, such as therapy for oral cavity disorders including tooth decay or periodontal disease, is scarce. The aim of the present study was to update such information based on studies assessing probiotics effects in oral cavity. A literature search in Pub-Med database was performed for English- or Spanish-language articles, using the following search terms: "probiotics" and "oral health"; no restrictions were used for publication dates.

\section{Mechanism of action of probiotics in oral cavity}

In oral cavity, probiotics can create a biofilm, acting as a protective lining for oral tissues against oral diseases. Such a biofilm keeps bacterial pathogens off oral tissues by filling a space pathogens would invade in the absence of the biofilm (4); and competing with cariogenic bacteria and periodontal pathogens growth (5).

\section{Probiotics and cariogenic pathogens}

Probiotics can reduce the risk for a high Streptococcus mutans level occurrence (6-8). An in vitro study has suggested Lactobacillus rhamnosus $G G$ can inhibit colonization by streptococcal cariogenic pathogens, and therefore reduce tooth decay incidence in children (7). Näse et al. (6) reported a reduced tooth decay incidence in children taking probiotic $L$. rhamnosus $G G$-enriched milk versus a control group of children taking milk without probiotic enrichment. Similar findings were observed by Ahola et al. (7) after administering the same probiotic. Nikawa et al. (8) showed that bovine milk fermented with Lactobacillus reuteri was effective against $S$. mutans, resulting in a reduced risk for tooth decay. Unlike Meurman et al. (9) and Nikawa et al. (8), Montalto et al. (10) reported an increased amount of Lactobacillus in saliva, with no reduction of S. mutans level, when administering to their patients Lactobacillus in a fluid form or in capsules to assess systemic effects. Also, Çaglar et al. (11), in a comparative study of S. mutans reduction effects by several probiotic administration forms, showed a reduced $S$. mutans level in patients receiving fluid or tablet probiotic forms. In an- other study by Çaglar et al. (12), S. mutans reduction effects were compared in subjects using probiotics-, xylitol-, or probiotics plus xylitol-enriched chewing gums, and a placebo control group; a reduced S. mutans level was observed in subjects using probiotics- or xylitol-enriched chewing gum; no synergic effect was seen when combining both agents. In another study by Çaglar et al. (13) probiotics effects were assessed after administration in a pacifier including a tablet that was dissolved in mouth after a 10 to 12 -minute suction; a reduced $S$. mutans level versus control group was found. Effects of an ice-cream containing Bifidobacterium lactis on S. mutans and Lactobacillus level in saliva were assessed by Çaglar et al. (14); a significantly reduced level was observed for S. mutans, but not for Lactobacillus. Effects of lactic strains used as probiotics in oral cavity were evaluated by Comelli et al. (5); Streptococcus thermophilus and Lactococcus lactis strains were shown to reduce cariogenic bacteria levels (particularly Streptococcus sobrinus and also Streptococcus oralis, Actinomyces naeslundii, and Veillonella dispar).

\section{Probiotics and periodontal disease}

The effect of probiotics tablets on gingivitis and different grades of periodontitis was studied by Grudianov et al. (15); probiotics treatment resulted in better microbiota normalization than control group. Krasse et al. (16) showed a significantly reduced gingival index and bacterial plaque amount in patients treated with $L$. reuteri than in a placebo group and concluded that this probiotic was effective to reduce gingivitis and bacterial plaque deposition in patients with moderate-to-severe gingivitis. According to Koll-Klais et al. (17), high levels of Lactobacillus in microbiota caused an $82 \%$ and $65 \%$ inhibition in Porphyromonas gingivalis and Prevotella intermedia growth, respectively.

Twetman et al. (18) used L. reuteri-containing chewing gum in 42 healthy patients and assessed its effects on crevicular fluid volume, cytokine (interleukin-1 $\beta$, interleukin-6, interleukin-10, and TNF- $\alpha$ ) levels, and bleeding on probing. Crevicular fluid volume, as well as TNF- $\alpha$ and interleukin- 8 levels, and bleeding were significantly reduced.

\section{Probiotics and halitosis}

Regular use of probiotics can help to control halitosis. After taking Weissella cibaria, reduced levels of volatile sulfide components produced by Fusobacterium nucleatum were observed by Kang et al. (19); the effect could be due to hydrogen peroxide production by $W$. cibaria, causing F. nucleatum inhibition. Streptococcus salivarius also suppress volatile sulfide effects, by competing for colonization areas with volatile sulfide-producing species (20). 


\section{Probiotics and Candida albicans}

C. albicans is a leading cause of infection in oral cavity; it is particularly common in the elderly and in immunocompromised patients. Hatakka et al. (21) showed a reduced prevalence of $C$. albicans after taking probiotics in cheese containing L. rhamnosus GG and Propionibacterium freudenreichii ssp. shermanii JS. Results obtained by Koll et al. (22) when assessing the effects of various Lactobacillus strains in oral cavity were markedly different; most strains suppressed growth of periodontal pathogens, including Aggregatibacter actinomycetemcomitans (60 out of 67 tested strains); Porphyromona gingivalis (35 out of 42 strains), $P$. intermedia (26 out of 42 strains), and cariogenic S. mutans (37 out of 67 strains). No inhibition was found, however, for $C$. albicans growth.

\section{Residence time of probiotics in oral cavity}

Residence time of probiotics in oral cavity after treatment withdrawal was studied by Çaglar et al. (11). A reduced $S$. mutans level was shown after a two-week use of a $L$. reuteri-enriched yogurt; effects were observed during use and for a few days after discontinuation. A loss of $L$. reuteri colonization was observed by Wolf et al. (23) two months after having discontinued probiotic use. L. rhamnosus GG administration and oral cavity colonization was studied by Yli-Knuuttila et al. (24); the authors concluded that permanent colonization in oral cavity was unlikely (although possible in some cases) and suggested the probiotic to be used on a regular basis. Binding strength of 17 Lactobacillus strains and 7 bifidobacteria strains to saliva and oral mucous membrane was variable in different strains, according to a study by Haukioja et al. (25); such a strength variation caused an increased residence time of probiotic in oral cavity. Latency time of probiotic $S$. salivarius $K 12$, 4 tablets/day for 3 days, was assessed in several oral cavity areas in a 35-day follow-up, by Horz et al. (26); probiotic could be found on oral mucous membrane, tongue and in stimulated saliva for more than 3 weeks, with a gradually reduced $S$. salivarius $K 12$ level being detected beginning 8 days after treatment withdrawal.

\section{Comments}

A literature review shows that oral probiotics use is associated to an improvement in oral health, which is mainly due to significantly reduced levels of cariogenic as well as periodontal pathogens; volume and cytokine levels are also reduced. Nevertheless, further studies will be needed to show probiotics efficacy to improve oral health.

\section{References}

1. Rasic JL. The role of dairy foods containing bifido and acidophilus bacteria in nutrition and health. N Eur Dairy J. 1983;4:80-8.

2. Brown AC, Valiere A. Probiotics and medical nutrition therapy. Nutr Clin Care. 2004;7:56-68.

3. Tanboga I, Çaglar E, Kargul B. Campaign of probiotic food consumption in Turkish children, oral perspectives 'Probiotics for your child'. Int J Pediatr Dent. 2003;13:59-64.

4. Caglar E, Kargul B, Tanboga I. Bacteriotherapy and probiotics' role on oral health. Oral Dis. 2005;11:131-7.

5. Comelli EM, Guggenheim B, Stingele F, Neeser JR. Selection of dairy bacterial strains as probiotics for oral health. Eur J Oral Sci. 2002;110:218-24.

6. Näse L, Hatakka K, Savilahti E, Saxelin M, Pönkä A, Poussa T, et al. Effect of long-term consumption of a probiotic bacterium, Lactobacillus rhamnosus GG, in milk on dental caries and caries risk in children. Caries Res. 2001;35:412-20.

7. Ahola AJ, Yli-Knuuttila H, Suomalainen T, Poussa T, Ahlström A, Meurman JH, et al. Short-term consumption of probiotic-containing cheese and its effect on dental caries risk factors. Arch Oral Biol. 2002;47:799-804.

8. Nikawa H, Makihira S, Fukushima H, Nishimura H, Ozaki Y, Ishida $\mathrm{K}$, et al. Lactobacillus reuteri in bovine milk fermented decreases the oral carriage of mutans streptococci. Int J Food Microbiol. 2004;95:219-23.

9. Meurman JH, Antila H, Korhonen A, Salminen S. Effect of Lactobacillus rhamnosus strain GG (ATCC 53103) on the growth of Streptococcus sobrinus in vitro. Eur J Oral Sci. 1995;103:253-8.

10. Montalto M, Vastola M, Marigo L, Covino M, Graziosetto R, Curigliano V, et al. Probiotic treatment increases salivary counts of lactobacilli: a double-blind, randomized, controlled study. Digestion. 2004;69:53-6.

11. Caglar E, Cildir SK, Ergeneli S, Sandalli N, Twetman S. Salivary mutans streptococci and lactobacilli levels after ingestion of the probiotic bacterium Lactobacillus reuteri ATCC 55730 by straws or tablets. Acta Odontol Scand. 2006;64:314-8.

12. Caglar E, Kavaloglu SC, Kuscu OO, Sandalli N, Holgerson PL, Twetman S. Effect of chewing gums containing xylitol or probiotic bacteria on salivary mutans streptococci and lactobacilli. Clin Oral Investig. 2007;11:425-9.

13. Caglar E, Kuscu OO, Cildir SK, Kuvvetli SS, Sandalli N. A probiotic lozenge administered medical device and its effect on salivary mutans streptococci and lactobacilli. Int J Paediatr Dent. 2008;18:35-9.

14. Caglar E, Kuscu OO, Selvi Kuvvetli S, Kavaloglu Cildir S, Sandalli N, Twetman S. Short-term effect of ice-cream containing Bifidobacterium lactis $\mathrm{Bb}-12$ on the number of salivary mutans streptococci and lactobacilli. Acta Odontol Scand. 2008;66:154-8.

15. Grudianov AI, Dmitrieva NA, Fomenko EV. [Use of probiotics Bifidumbacterin and Acilact in tablets in therapy of periodontal inflammations]. Stomatologiia (Mosk). 2002;81:39-43.

16. Krasse P, Carlsson B, Dahl C, Paulsson A, Nilsson A, Sinkiewicz G. Decreased gum bleeding and reduced gingivitis by the probiotic Lactobacillus reuteri. Swed Dent J. 2006;30:55-60.

17. Kõll-Klais P, Mändar R, Leibur E, Marcotte H, Hammarström L, Mikelsaar M. Oral lactobacilli in chronic periodontitis and periodontal health: species composition and antimicrobial activity. Oral Microbiol Immunol. 2005;20:354-61.

18. Twetman S, Derawi B, Keller M, Ekstrand K, Yucel-Lindberg T, Stecksen-Blicks C. Short-term effect of chewing gums containing probiotic Lactobacillus reuteri on the levels of inflammatory mediators in gingival crevicular fluid. Acta Odontol Scand. 2009;67:1924.

19. Kang MS, Kim BG, Chung J, Lee HC, Oh JS. Inhibitory effect of Weissella cibaria isolates on the production of volatile sulphur compounds. J Clin Periodontol. 2006;33:226-32.

20. Burton JP, Chilcott CN, Tagg JR. The rationale and potential for the reduction of oral malodour using Streptococcus salivarius probiotics. Oral Dis. 2005;11 Suppl 1:29-31. 
21. Hatakka K, Ahola AJ, Yli-Knuuttila H, Richardson M, Poussa T, Meurman JH, et al. Probiotics reduce the prevalence of oral candida in the elderly--a randomized controlled trial. J Dent Res. 2007;86:125-30.

22. Kõll P, Mändar R, Marcotte H, Leibur E, Mikelsaar M, Hammarström L. Characterization of oral lactobacilli as potential probiotics for oral health. Oral Microbiol Immunol. 2008;23:139-47.

23. Wolf BW, Garleb KA, Ataya DG, Casas IA. Safety and tolerance of Lactobacillus reuteri in healthy adult male subjects. Microb Ecol Health Dis. 1995;8:41-50.

24. Yli-Knuuttila H, Snäll J, Kari K, Meurman JH. Colonization of Lactobacillus rhamnosus GG in the oral cavity. Oral Microbiol Immunol. 2006;21:129-31.

25. Haukioja A, Yli-Knuuttila H, Loimaranta V, Kari K, Ouwehand $\mathrm{AC}$, Meurman JH, et al. Oral adhesion and survival of probiotic and other lactobacilli and bifidobacteria in vitro. Oral Microbiol Immunol. 2006;21:326-32.

26. Horz HP, Meinelt A, Houben B, Conrads G. Distribution and persistence of probiotic Streptococcus salivarius K12 in the human oral cavity as determined by real-time quantitative polymerase chain reaction. Oral Microbiol Immunol. 2007;22:126-30. 